\title{
PRODUÇÃO DE MUDAS DE CARAMBOLEIRAS 'B-10' E 'GOLDEN STAR': II - MARCHA DE ABSORÇÃO E ACÚMULO DE NUTRIENTES ${ }^{1}$
}

\author{
DANILO EDUARDO ROZANE ${ }^{2}$, RENATO DE MELLO PRADO ${ }^{3}$, WILLIAM NATALE ${ }^{3}$, \\ LILIANE MARIA ROMUALDO ${ }^{4}$, HENRIQUE ANTUNES DE SOUZA ${ }^{5}$, \\ SILVIA HELENA MODENESE GORLA DA SILVA ${ }^{2}$
}

\begin{abstract}
RESUMO - A participação do Brasil no mercado externo de frutas tem aumentado consideravelmente e com potencial para crescer ainda mais. A constante ascensão dos dados de exportação brasileira é resultado da combinação de avanços tecnológicos do setor produtivo e de acesso a novos mercados consumidores. A caramboleira apresenta-se como uma excelente opção de cultivo de frutas exóticas, com grande potencial para atender ao mercado interno e às exportações. Assim, objetivou-se avaliar a marcha de absorção e de acúmulo de nutrientes em mudas de caramboleiras cultivadas em solução nutritiva. $\mathrm{O}$ experimento foi realizado em parcelas subdivididas, sendo utilizadas como parcela as duas cultivares de caramboleira ('B10 ' e 'Golden Star') e, como subparcelas, cinco épocas de coleta de plantas, realizadas aos 208; 233; 258; 283 e 308 dias após o transplantio para a solução nutritiva. O delineamento foi inteiramente casualizado, com três repetições. As mudas foram cultivadas em vasos $(8 \mathrm{~L}) \mathrm{com}$ solução nutritiva $(\mathrm{pH}=5,5 \pm 0,5)$, com aeração. O experimento iniciou-se em 24-08-2005. Nos diferentes órgãos das mudas (folhas, caule e raízes), determinaram-se a marcha de absorção, o acúmulo de nutrientes e os índices nutricionais. Não houve diferenças no acúmulo de nutrientes entre as mudas de caramboleira de ambas as cultivares, sendo a ordem decrescente dos nutrientes em cada muda de 'B-10', no final do período experimental: $\mathrm{N}>\mathrm{K}>\mathrm{Ca}>\mathrm{Mg}>$ $\mathrm{S}>\mathrm{P}>\mathrm{Fe}>\mathrm{Mn}>\mathrm{B}>\mathrm{Cu}>\mathrm{Zn}$. Para a 'Golden Star', a ordem foi: $\mathrm{N}>\mathrm{K}>\mathrm{Ca}>\mathrm{Mg}>\mathrm{P}>\mathrm{S}>\mathrm{Fe}>\mathrm{Mn}$ $>\mathrm{B}>\mathrm{Cu}>\mathrm{Zn}$. Para as duas cultivares, o acúmulo médio foi maior nas folhas $>$ caule $>$ raízes. O período de maior exigência para 'B-10' foi entre 208 - 233 e, para 'Golden Star', entre 233 - 283 dias após o transplantio. As diferentes taxas de acumulação líquida dos nutrientes, nos diferentes órgãos da caramboleira, nem sempre acompanharam a taxa de acumulação de nutrientes do respectivo órgão.
\end{abstract}

Termos para indexação: Averrhoa carambola, exigência nutricional, solução nutritiva, marcha de absorção.

\section{PRODUCTION OF STAR FRUIT 'B-10'AND 'GOLDEN STAR' SEEDLINGS: II - ABSORPTION RATE AND ACUMULATION OF NUTRIENTS}

\begin{abstract}
Brazil's participation in the external market of fruits has increased considerably with the potential to grow further. The constant rise of the Brazilian exportation data is the result of a combination of technological advances in the productive sector and access to new markets. The star fruit is presented as an excellent option for cultivation of exotic fruits, with great potential to attend the domestic market and exportation. Thus, the objective was to assess absorption rate and accumulation of nutrients in star fruit seedlings, grown in nutrient solution. The experiment was conducted in split plots being used as part of the two cultivars of star fruit ('B-10' and 'Golden Star') and as subplots, five plant collecting periods, realized at 208,233, 258, 283 and 308 days after transplanting to the nutrient solution. The experimental design was completely randomized with three replications. The seedlings were grown in pots $(8 \mathrm{~L})$ with nutrient solution $(\mathrm{pH}=5.5 \pm 0.5)$ with aeration. The experiment started on 08.24.2005. In different plant organs (leaves, stems and roots), absorption rate, accumulation of nutrients and nutritional indices were determined. It did not have differences in the accumulation of nutrients in the star fruit seedlings for both cultivars, the decreasing order of the nutrients in each 'B-10'seedlings, in the end of the experimental period, was: $\mathrm{N}>\mathrm{K}>\mathrm{Ca}>\mathrm{Mg}$ $>\mathrm{S}>\mathrm{P}>\mathrm{Fe}>\mathrm{Mn}>\mathrm{B}>\mathrm{Cu}>\mathrm{Zn}$. For 'Golden Star' the decreasing order was: $\mathrm{N}>\mathrm{K}>\mathrm{Ca}>\mathrm{Mg}>\mathrm{P}>\mathrm{S}$ $>\mathrm{Fe}>\mathrm{Mn}>\mathrm{B}>\mathrm{Cu}>\mathrm{Zn}$. For the two cultivars, the average accumulation was bigger in leaves $>$ stem $>$ roots. The period of bigger requirement for 'B-10' was between 208 - 233 and, for 'Golden Star', between 233 - 283 days after the transplantation. The different rates of nutrient liquid accumulation, in the different organs of star fruit trees, not always followed the nutrient accumulation rate of the respective organ.

Index terms: Averrhoa carambola L., nutritional requeriments, nutrient solution, absorption rate.

\footnotetext{
'(Trabalho 018-11). Recebido em: 04-01-2011. Aceito para publicação em: 31-05-2011. Parte da Tese de Doutorado do primeiro autor ${ }^{2}$ Prof. Assistente Doutor, Universidade Estadual Paulista "Julio de Mesquita Filho" Unesp-Câmpus Experimental de Registro, Rua ${ }^{3}$ Prof. Adjunto, Dept ${ }^{\circ}$. de Solos e Adubos, FCAV/Unesp. Bolsista PQ do CNPq. E-mail: rmprado@fcav.unesp.br; natale@fcav.unesp.br ${ }^{4}$ Doutoranda, USP/FZEA. E-mail: lilianeromualdo@yahoo.com.br
} Nelson Brihi Badur, 430, Vila Tupy - 11900-000 Registro-SP. E-mail: danilorozane@registro.unesp.br; silvia@registro.unesp.br

${ }^{5}$ Pesquisador Embrapa Caprinos e Ovinos. E-mail: henrique@cnpc.embrapa.br
\end{abstract}




\section{INTRODUÇÃO}

A marcha de acúmulo de nutrientes fornece informações sobre a exigência nutricional das plantas em sua fase de ontogênese, indicando épocas adequadas à adição de elementos essenciais, permitindo planejar métodos racionais de cultivo e aplicação de fertilizantes.

Em vista da expansão da cultura da caramboleira, bem como da crescente popularização do fruto nos mercados consumidores interno e externo, e considerando-se a carência de informações científicas sobre nutrição mineral, especialmente em relação à marcha de absorção de nutrientes nas diferentes fases de desenvolvimento da cultura, objetivou-se determinar o crescimento e o acúmulo de elementos em mudas de caramboleira 'B-10' e 'Golden Star'.

\section{MATERIAL E MÉTODOS}

Como apresentado em Rozane et al. (2011), o experimento foi conduzido em casa de vegetação, na FCAV/UNESP, Câmpus de Jaboticabal - SP, sendo que, posteriormente à determinação da massa de matéria seca das diferentes partes da planta (raízes, caule e folhas), os materiais foram moídos e armazenados. Na sequência, determinaram-se os teores de nutrientes no tecido vegetal, empregando-se a metodologia descrita por Bataglia et al. (1983).

O acúmulo dos nutrientes foi obtido pelo produto entre o teor do elemento no órgão da muda e a massa de matéria seca correspondente a cada parte da planta e época avaliada. $\mathrm{O}$ acúmulo de nutrientes na planta inteira deu-se pela soma das quantidades presentes nas raízes, no caule e nas folhas.

Com base nos resultados, foram realizadas análises de variância (teste F) para as diversas características estudadas, e o estudo da regressão, para tempo de cultivo, com o auxílio do programa ESTAT (1992). Em todas as variáveis, empregou-se o modelo de regressão, que resultou em significância pelo teste $\mathrm{F}$, e que melhor representou a característica estudada.

Para o modelo logístico, empregou-se a equação citada por Hoffmam e Vieira (1977), representada por:

$$
Y=\frac{a}{1+e^{-k(x-x c)}}
$$

em que, $a$ : é o máximo acumulado assintótico; $e$ : é o inverso do logaritmo neperiano; $k$ : é a taxa média de acúmulo; $x$ : dias após o transplantio, e $x c$ : é o tempo necessário para atingir $50 \%$ do acúmulo máximo assintótico.

Para o modelo exponencial, a equação de ajuste utilizada foi representada por:

$$
Y=Y_{0}+A_{1} e^{\left(x / t_{1}\right)}
$$

em que, $Y_{0}$ : é a assíntota inferior; $A_{1}$ : amplitude de crescimento; $e$ : é o inverso do logaritmo neperiano; $x$ : dias após o transplantio, e $t_{1}$ : é a taxa de crescimento.

Foram determinados, ainda, os índices nutricionais estimados pela fórmula proposta por Welbank (1962):

$T A R N=\frac{(N 2-N 1)(\ln M 2-\ln M 1)}{(t 2-t 1)(M 2-M 1)}=m g$ por g por dia em que, TALON: é a Taxa de absorção relativa dos nutrientes; $N 1$ e $N 2$ : quantidade do nutriente no órgão vegetal referente aos tempos $t 1$ e $t 2$, respectivamente; $M 1$ e $M 2$ : massa da matéria seca total da planta referente aos tempos $t 1$ e $t 2$, respectivamente, e ln é o logaritmo neperiano.

TALON $=\frac{(N 2-N 1)(\ln m 2-\ln m 1)}{(t 2-t 1)(m 2-m 1)}=m g$ por $g$ por dia

em que, : Taxa de Acumulação Líquida Organogênica do Nutriente; $m 1$ e $m 2$ : massa da matéria seca do órgão vegetal referente aos tempos $t 1$ e $t 2$, respectivamente.

\section{RESULTADOS E DISCUSSÃO}

A similaridade das equações dos acúmulos de nutrientes que acompanharam a massa da matéria seca (ROZANE et al., 2011), resultando na maior ocorrência dos ajustes ao modelo linear, pode ser explicada pelo fato de as mudas de caramboleira, nas presentes condições experimentais, possuírem em média 6,3 e $6,0 \%$ do peso dos nutrientes avaliados na massa da matéria seca total, respectivamente, para a 'B-10' e a 'Golden Star' (Figuras 1; 2; 3 e 4). Lima Filho et al. (1997a) relataram, também, em cultivo de estévia, que a acumulação de nutrientes acompanha a taxa de crescimento da planta.

Não houve diferença significativa entre as cultivares para o acúmulo de $\mathrm{K}, \mathrm{S}$, Fe e $\mathrm{Zn}$ nas raízes; $\mathrm{N}, \mathrm{K}, \mathrm{Ca}, \mathrm{Mg}, \mathrm{B}$ e Cu no caule; $\mathrm{N}, \mathrm{P}, \mathrm{K}, \mathrm{Ca}, \mathrm{Mg}, \mathrm{B}$, $\mathrm{Cu}, \mathrm{Fe}, \mathrm{Mn}$ e $\mathrm{Zn}$ nas folhas; e N, P, K, Ca, Mg, B e Fe na planta inteira. Não houve interação entre cultivares e tempo de cultivo para $\mathrm{Mn}$ nas raízes; $\mathrm{K}, \mathrm{Ca}$ e $\mathrm{B}$ no caule; $\mathrm{N}, \mathrm{K}, \mathrm{Ca}, \mathrm{Mg}, \mathrm{Cu}$ e Fe nas folhas; e, $\mathrm{K}, \mathrm{Ca}$, $\mathrm{B}, \mathrm{Fe}$ e $\mathrm{Zn}$ na planta inteira (Tabela 1). Os maiores acúmulos de nutrientes foram registrados no final do período experimental, em ambas as cultivares. Contudo, em função do tempo de cultivo, o acúmulo de nutrientes apresentou comportamento variável em função do órgão e do nutriente analisado (Figuras 1; 2; 3 e 4), o que também corrobora as observações realizadas por Lima Filho et al. (1997a,b) e Souza e Coelho (2001). 
No final do período experimental, as mudas de caramboleira 'B-10' e 'Golden Star' apresentaram, respectivamente, acúmulo de macronutrientes (mg por planta) aos 308 dias, para as raízes, na quantidade de: $\mathrm{N}=253$ e $292 ; \mathrm{P}=49$ e $69 ; \mathrm{K}=124$ e $147 ; \mathrm{Ca}$ $=42$ e $62 ; \mathrm{Mg}=26$ e 37 e $\mathrm{S}=43$ e $46 ;$ no caule, $\mathrm{N}$ $=327$ e $306 ; \mathrm{P}=65$ e $64 ; \mathrm{K}=255$ e $227 ; \mathrm{Ca}=155$ e $139 ; \mathrm{Mg}=77$ e 75 e $\mathrm{S}=39$ e 38 e nas folhas $\mathrm{N}=$ 843 e $780 ; \mathrm{P}=49$ e $44 ; \mathrm{K}=564$ e $539 ; \mathrm{Ca}=250$ e 229; $\mathrm{Mg}=140$ e 129 e $\mathrm{S}=84$ e 91 . O acúmulo de micronutrientes ( $\mu$ g por planta) aos 308 dias, para as raízes, foi de: $\mathrm{B}=185$ e $257 ; \mathrm{Cu}=531$ e $393 ; \mathrm{Fe}=$ 7026 e $8365 ; \mathrm{Mn}=294$ e 297 e $\mathrm{Zn}=185$ e $245 ;$ no caule, $\mathrm{B}=308$ e $247 ; \mathrm{Cu}=688$ e $712 ; \mathrm{Fe}=1338$ e $726 ; \mathrm{Mn}=329$ e 282 e $\mathrm{Zn}=547$ e 524 e nas folhas, B $=1488$ e $1381 ; \mathrm{Cu}=374$ e $326 ; \mathrm{Fe}=3514$ e $3453 ; \mathrm{Mn}$ $=2999$ e 3101 e Zn= 677 e 580 (Figuras 1; 2; 3 e 4).

Pode-se observar que, do total de nutrientes absorvidos, o acúmulo de $\mathrm{N}, \mathrm{K}, \mathrm{Ca}, \mathrm{Mg}, \mathrm{S}, \mathrm{B}, \mathrm{Mn}$ e $\mathrm{Zn}$ foi maior nas folhas, enquanto o $\mathrm{Fe}$ foi maior nas raízes, e o $\mathrm{Cu}$, no caule das mudas de caramboleira (Figuras 1; 2; 3 e 4). Resultados semelhantes, quanto ao local de acúmulo, foram observados em mudas de caramboleira por Freitas (2008), e em mudas de goiabeira, por Franco et al. (2007), com exceção do Cu em mudas de goiabeiras, por Franco et al. (2008), cultivadas nas mesmas condições de casa de vegetação. $\mathrm{O}$ maior acúmulo de $\mathrm{Cu}$ no caule pode ser explicado pela aplicação da pasta cúprica após a realização da enxertia, o qual ficou aderido à superfície do corte e, posteriormente, suberizado pela cicatrização do tecido, não sendo assim completamente removido no processo de lavagem no laboratório.

$\mathrm{O}$ acúmulo de nutrientes no final do período experimental, nas raízes da 'Golden Star', foi maior em relação à 'B-10' para N (15\%), P (41\%), K (19\%), $\mathrm{Ca}(48 \%), \operatorname{Mg}(42 \%), \mathrm{S}(7 \%), \mathrm{B}(39 \%), \mathrm{Fe}(19 \%), \mathrm{Mn}$ ( $1 \%)$ e $\mathrm{Zn}(32 \%)$, o que se deve, provavelmente, ao maior acúmulo da massa de matéria seca nas raízes (ROZANE et al., 2011); entretanto, na 'B-10', o acúmulo de $\mathrm{P}(2 \%), \mathrm{S}(3 \%), \mathrm{Fe}(46 \%)$, Mn (14\%), $\mathrm{Zn}(4 \%)$ foi maior no caule em relação à 'Golden Star'. Para o acúmulo de nutrientes nas folhas, somente o $\mathrm{S}$ foi significativo, sendo que a 'Golden Star' acumulou $8 \%$ a mais que a 'B-10'. Podem-se destacar as maiores variações para $\mathrm{P}, \mathrm{Ca}$ e $\mathrm{Mg}$. Tais diferenças, especialmente nas raízes, devem-se à diferença entre as cultivares. Observação semelhante foi feita por Freitas (2008) que, cultivando caramboleira 'Nota-10' em condições similares, constatou divergência quanto ao total de nutrientes acumulados em raízes, caule e folhas, atribuíndo essas diferenças ao material genético e ao tempo de experimentação, já que as condições de cultivo e as concentrações de elementos na solução nutritiva foram semelhantes. Marschner (1995) relata que os parâmetros cinéticos de absorção de nutrientes sofrem influência genética e estão relacionados às características morfológicas e fisiológicas da planta.

Do total de nutrientes acumulados, observase, dentre os que apresentaram diferenças entre as cultivares (Tabela 1), que na 'B-10' houve maior incremento em relação à 'Golden Star' para $\mathrm{Cu}(7 \%)$ e Zn (6\%); entretanto, na 'Golden Star', a absorção de $\mathrm{S}$ e $\mathrm{Mn}$ foi, respectivamente, 1 e $6 \%$ maior que na 'B-10' (Figuras 1; 2; 3 e4). Destaca-se, portanto, a pequena variação no acúmulo de nutrientes na planta inteira entre as duas cultivares estudadas.

$\mathrm{O}$ acúmulo médio dos nutrientes pelas mudas da caramboleira 'B-10' obedeceu à seguinte sequência: $\mathrm{N}>\mathrm{K}>\mathrm{Ca}>\mathrm{Mg}>\mathrm{S}>\mathrm{P}>\mathrm{Fe}>\mathrm{Mn}>\mathrm{B}>\mathrm{Cu}>$ Zn (Figuras 1 e 2). Para a 'Golden Star', a sequência foi a mesma, excetuando-se a inversão entre o $\mathrm{S}$ e o P (Figuras 3 e 4). Essa ordem de acúmulo de nutrientes diverge da verificada por Freitas (2008) no mesmo sistema de cultivo para a caramboleira 'Nota-10'. Variações na ordem de absorção de nutrientes em mudas de frutíferas são comumente relatadas na literatura, quando se empregam materiais genéticos e meios de cultivo distintos, além do tempo de experimentação, a exemplo da gravioleira (CHU et al., 2001; BARBOSA et al., 2003) e da goiabeira (AUGOSTINHO et al., 2008; FRANCO et al., 2007; FRANCO et al., 2008).

Rozane et al. (2007) verificaram que o $\mathrm{N}$ e o $\mathrm{K}$ são os nutrientes mais requeridos na fase inicial de desenvolvimento da caramboleira. A alta exigência de $\mathrm{N}$ e $\mathrm{K}$ na fase inicial de desenvolvimento devese, possivelmente, à intensa atividade metabólica nesta fase.

A despeito de a Taxa de Acumulação Líquida Organogênica - TALON, nos diversos órgãos das mudas, nem sempre acompanhar a Taxa de Crescimento Relativo - TCR (ROZANE et al., 2011), dos tecidos da caramboleira, a Taxa de Absorção Relativa - TARN, teve acompanhamento satisfatório da TCR devido, provavelmente, ao acúmulo da massa de matéria seca representar a maior expressão destes índices.

As cultivares apresentaram, no período de 208 a 233 DAT, maior TALON, ocorrendo a maior alocação de nutrientes nas folhas, em relação aos demais órgãos, para $\mathrm{N}, \mathrm{K}, \mathrm{Ca}, \mathrm{Mg}, \mathrm{S}, \mathrm{B}, \mathrm{Fe}, \mathrm{Mn}$ e $\mathrm{Zn}$, enquanto o $\mathrm{P}$ se acumulou, preferencialmente, no caule, e o $\mathrm{Cu}$, nas raízes, corroborando os trabalhos de Lima Filho et al. (1997a b).

Entre os períodos de 283 - 308 DAT para 'B-10', e 233 - 283 DAT para 'Golden Star', o 
Fe apresentou resultados incoerentes da TALON nas raízes, o que provavelmente deve ter ocorrido devido ao meio de cultivo empregado e à inadequada remoção de todo elemento no procedimento de lavagem. O Mn, entretanto, quase em todos os períodos analisados para 'B-10' e 'Golden Star', apresentou a maior TALON nas folhas (Tabela 2), corroborando as observações de Freitas (2008), em estudo de marcha de absorção com mudas de caramboleira 'Nota 10'.

Para 'B-10' de 233 a 258 DAT, com exceção do $\mathrm{P}, \mathrm{Cu}$ e $\mathrm{Zn}$, que tiveram maior direcionamento para as raízes e, considerando as observações feitas para $\mathrm{Mn}$ e $\mathrm{Zn}$, houve unanimidade quanto à maior TALON (Tabela 2), ou seja, maior direcionamento dos demais nutrientes para as folhas que, no referido período, tiveram, juntamente com o caule, a maior TCR entre os órgãos (ROZANE et al., 2011).

Para 'Goden Star' de 233 a 258 DAT, à exceção do $\mathrm{Ca}, \mathrm{Mg}, \mathrm{Cu}$ e $\mathrm{Zn}$, que tiveram maior direcionamento para o caule, e considerando as observações feitas para $\mathrm{Mn}$ e Zn, os demais nutrientes tiveram maior TALON nas raízes, as quais, no referido período, tiveram, juntamente com o caule, maior TCR que as folhas (Tabela 2).
Para 'B-10' e 'Golden Star', entre os períodos de 258 - 238 e 283 - 308 DAT, houve variação entre a maior TALON dos nutrientes quanto ao órgão de destino. Porém, de maneira geral, houve associação da maior TALON (Tabela 2) com o maior TCR (ROZANE et al., 2011).

Pelo fato de a TALON ser o resultado dos processos que levam, tanto à acumulação quanto à perda do nutriente para outros órgãos ou para o meio externo, seria esperado encontrar-se resultados negativos, indicando a perda líquida de um dado nutriente. Contudo, a não ocorrência deste fato (Tabelas 2 e 3 ), aliada ao pleno desenvolvimento vegetativo justificam a constante absorção de nutrientes. As condições de cultivo hidropônico, a solução empregada e a periodicidade de troca desta, bem como o espaçamento das mudas não limitaram o desenvolvimento das plantas e, por consequência, resultaram em valores positivos da TARN.

De maneira geral, as maiores TARNs são observadas nos períodos inicias de avaliação (Tabelas 2 e 3), devido ao pequeno acúmulo de massa de matéria seca nas mudas de caramboleira (ROZANE et al., 2011) que, no quociente da fórmula, evidenciam a maior concentração de nutrientes e, portanto, as maiores TARNs.

TABELA 1 - Valor de F e coeficientes de variação dos fatores cultivar, tempo de cultivo e sua interação sobre acúmulo de nutrientes nos diferentes órgãos das mudas de caramboleiras 'B-10' e 'Golden Star'

\begin{tabular}{|c|c|c|c|c|c|c|c|c|c|c|c|}
\hline Fatores & $\mathrm{N}$ & $\mathrm{P}$ & $\mathrm{K}$ & $\mathrm{Ca}$ & $\mathrm{Mg}$ & $\mathrm{S}$ & $\mathrm{B}$ & $\mathrm{Cu}$ & $\mathrm{Fe}$ & $\mathrm{Mn}$ & $\mathrm{Zn}$ \\
\hline & & & & & & - Kalzes & & & & & \\
\hline Tempo cultivo $(\mathrm{T})$ & $95,71 * *$ & $74,18^{* *}$ & $62,28 * *$ & $12,70 * *$ & $72,24 * *$ & $37,79 * *$ & $78,96^{* *}$ & $135,66^{* *}$ & $* 80,76 * *$ & $37,89 * *$ & $21,22 * *$ \\
\hline Cultivares (C) & $95,71 * *$ & $74,18^{* *}$ & $62,28 * *$ & $12,70 * *$ & $72,24 * *$ & $37,79 * *$ & $78,96 * *$ & $135,66^{* *}$ & $* 80,76^{* *}$ & $37,89 * *$ & $21,22 * *$ \\
\hline Interação $(\mathrm{C}$ x T) & $13,25 * *$ & $15,96^{* *}$ & $9,33 * *$ & $3,34 * *$ & $11,30 * *$ & $12,28 * *$ & $13,15 * *$ & $21,29 * *$ & $10,43 * *$ & $1,81 \mathrm{~ns}$ & $5,39 * *$ \\
\hline $\mathrm{CV}(\%)^{(1)}$ & 10,0 & 13,1 & 10,2 & 15,7 & 11,5 & 14,1 & 9,3 & 10,5 & 10,1 & 16,1 & 12,9 \\
\hline $\mathrm{CV}(\%)^{(2)}$ & 9,9 & 10,3 & 11,4 & 26,6 & 12,1 & 12,9 & 10,1 & 14,8 & 10,6 & 18,3 & 13,7 \\
\hline Tempo cultivo (T) & $184,51 * *$ & $* 167,57 * *$ & $64,88 * *$ & $32,63 * *$ & $165,09 * *$ & $42,49 * *$ & $42,82 * *$ & $196,89 * *$ & $* 99,79 * *$ & $72,46 * *$ & $16,47 * *$ \\
\hline Cultivares (C) & $4,52 \mathrm{~ns}$ & $167,57 * *$ & $0,02 \mathrm{~ns}$ & $6,25 \mathrm{~ns}$ & $0,93 \mathrm{~ns}$ & $13,46^{*}$ & $4,59 \mathrm{~ns}$ & $2,06 \mathrm{~ns}$ & $255,10 * *$ & $62,69 * *$ & $94,45 * *$ \\
\hline Interação $(\mathrm{C} \times \mathrm{T})$ & $8,52 * *$ & $11,04 * *$ & $2,10 \mathrm{~ns}$ & $2,66 \mathrm{~ns}$ & $6,74 * *$ & $4,10^{*}$ & $2,75 \mathrm{~ns}$ & $7,95 * *$ & $13,54 * *$ & $9,02 * *$ & $16,47 * *$ \\
\hline $\mathrm{CV}(\%)^{(1)}$ & 11,4 & 9,7 & 17,7 & 11,1 & 14,5 & 16,2 & 18,5 & 21,5 & 8,9 & 9,2 & 9,4 \\
\hline $\operatorname{CV}(\%)^{(2)}$ & 9,3 & 8,0 & 15,7 & 17,5 & 10,5 & 11,3 & 23,5 & 15,5 & 14,8 & 9,6 & 16,1 \\
\hline Tempo cultivo $(\mathrm{T})$ & $196,85 * *$ & $122,10 * *$ & $106,32 * *$ & $129,77 * *$ & $153,40 * *$ & $131,35 * *$ & $380,68 * *$ & $* 316,12 * *$ & *327,11** & $152,56^{* *}$ & $* 81,35 * *$ \\
\hline Cultivares (C) & $0,35 \mathrm{~ns}$ & $0,02 \mathrm{~ns}$ & $0,23 \mathrm{~ns}$ & $1,62 \mathrm{~ns}$ & $1,44 \mathrm{~ns}$ & $10,10^{*}$ & $2,17 \mathrm{~ns}$ & $5,68 \mathrm{~ns}$ & $0,47 \mathrm{~ns}$ & $1,35 \mathrm{~ns}$ & $3,37 \mathrm{~ns}$ \\
\hline Interação $(\mathrm{C}$ x T) & $2,37 \mathrm{~ns}$ & $5,36 * *$ & $1,80 \mathrm{~ns}$ & $2,36 \mathrm{~ns}$ & $1,50 \mathrm{~ns}$ & $4,93 * *$ & $3,45^{*}$ & $1,80 \mathrm{~ns}$ & $0,98 \mathrm{~ns}$ & $4,72 *$ & $6,95 * *$ \\
\hline $\mathrm{CV}(\%)^{(1)}$ & 9,5 & 10,9 & 13,2 & 15,2 & 14,1 & 7,3 & 10,7 & 15,7 & 12,6 & 6,7 & 9,0 \\
\hline $\mathrm{CV}(\%)^{(2)}$ & 10,4 & 10,9 & 12,4 & 13,2 & 12,1 & 11,6 & 9,4 & 12,2 & 11,9 & 11,0 & 9,8 \\
\hline Tempo cultivo (T) & $413,50 * *$ & 259,15 & $150,9 * *$ & $199,25 * *$ & 299,65 & $\begin{array}{l}\text { anta Inte } \\
156,17^{*}\end{array}$ & $50,42 \cdot$ & 495,45 & $* 237,37 * *$ & $181,93 * *$ & $* 69,08 * *$ \\
\hline Cultivares (C) & $0,01 \mathrm{~ns}$ & $2,31 \mathrm{~ns}$ & $0,01 \mathrm{~ns}$ & $0,84 \mathrm{~ns}$ & $0,06 \mathrm{~ns}$ & $16,73^{*}$ & $1,35 \mathrm{~ns}$ & $11,19^{*}$ & $2,87 \mathrm{~ns}$ & $8,42 *$ & $14,21^{*}$ \\
\hline Interação $(\mathrm{C}$ x T) & $6,72 * *$ & $10,75^{* *}$ & $1,49 \mathrm{~ns}$ & $2,08 \mathrm{~ns}$ & $3,03 *$ & $3,55^{*}$ & $2,39 \mathrm{~ns}$ & $4,23 *$ & $7,58 \mathrm{~ns}$ & $5,72 * *$ & $1,34 \mathrm{~ns}$ \\
\hline $\mathrm{CV}(\%)^{(1)}$ & 7,1 & 8,1 & 11,9 & 11,8 & 12,7 & 4,5 & 9,9 & 9,2 & 4,2 & 6,1 & 7,4 \\
\hline $\mathrm{CV}(\%)^{(2)}$ & 6,4 & 6,7 & 9,8 & 8,8 & 7,9 & 8,2 & 8,7 & 8,9 & 8,1 & 9,4 & 8,9 \\
\hline
\end{tabular}


TABELA 2- Taxa de acumulação líquida organogênica (TALON) e taxa de absorção relativa (TARN) de nutrientes nos diferentes órgãos de mudas de caramboleira 'B-10', cultivadas em solução nutritiva

\begin{tabular}{|c|c|c|c|c|c|c|c|c|c|c|c|}
\hline rgão & Períodos & $\mathrm{N}$ & $\mathrm{K}$ & $\mathrm{Ca}$ & $\mathrm{Mg}$ & S & B & $\mathrm{Cu}$ & $\mathrm{Fe}$ & $\mathrm{Mn}$ & $\mathrm{Zn}$ \\
\hline & dias & & $-\mathrm{mg}_{1}$ & por & dia - & -- & & -1 & lg po & g por di & $1 \mathrm{a}$ \\
\hline & & & & & TALON & & & & & & \\
\hline & $208-233$ & 0,190 & $0,0360,068$ & 0,029 & 0 & 0,0 & 013 & 0,441 & 2,682 & 0,094 & 0,032 \\
\hline & $233-258$ & 0,056 & $0,0290,015$ & 0,006 & 0,019 & 0,001 & 0,042 & 0,296 & 3,232 & 0,090 & 0,165 \\
\hline SIE- & $258-283$ & 0,304 & $0,0240,18$ &, 043 & 0,026 & $0,00^{-}$ & ,288 & 0,053 & 5,653 & 0,531 & 0,048 \\
\hline & 283-308 & 0,394 & $0,0620,128$ & 0,049 & 0,038 & 0,082 & 0,140 & 2,324 & 11,986 & 0,300 & 0,070 \\
\hline & $208-233$ & 0,461 & $0,150 \quad 0,452$ & 0,142 & 0,141 & 0,064 & 0,006 & 0,148 & 0,529 & 0,016 & 1,112 \\
\hline Caule & $233-258$ & 0,068 & $0,0010,000$ & 0,001 & 0,001 & 0,002 & 0,084 & 0,107 & 0,098 & 0,101 & 0,017 \\
\hline - tur & $258-283$ & 0,396 & $0,0580,157$ & 0,210 & 0,072 & 0,03 & 0,70 & 0,856 & 2,759 & 0,013 & 0,186 \\
\hline & 283-308 & 0,120 & $0,0120,1$ & 0,0 & 0,054 & 0,00 & 0,00 & 0,468 & 0,059 & 0,262 & 0,006 \\
\hline & $208-233$ & 2,000 & $0,1171,620$ & 0,689 & 0,373 & 0,29 & 2,410 & 0,368 & 5,031 & 10,383 & 1,405 \\
\hline & $233-258$ & 0,225 & $\begin{array}{lll}0,001 & 0,197\end{array}$ & 0,122 & 0,034 & 0,036 & 0,39 & 0,276 & 0,095 & 0,224 & 0,022 \\
\hline $\mathrm{In}$ & $258-283$ & 0,689 & $\begin{array}{ll}0,039 & 0,374\end{array}$ & 0,099 & 0,085 & 0,049 & 1,587 & 0,488 & 5,216 & 2,117 & 0,619 \\
\hline & $283-308$ & 0,244 & $0,0160,073$ & 0,118 & $\begin{array}{r}0,061 \\
\text { TARN }\end{array}$ & 0,009 & 0,568 & 0,025 & 0,829 & 0,203 & 0,076 \\
\hline & $208-233$ & 0,822 & $0,1000,666$ & 0,266 & 0,164 & 0,118 & 0,725 & 0,305 & 2,555 & 3,135 & 0,825 \\
\hline lanta & $233-258$ & 0,133 & $0,0070,089$ & 0,053 & 0,018 & $0,01^{\top}$ & 0,206 & 0,223 & 0,832 & 0,151 & 0,055 \\
\hline & $258-28$ & 0,520 & $0,043 \quad 0,26$ & 0,12 & 0,07 & 0,03 & 1,05 & 0,531 & 4,454 & 1,119 & 0,369 \\
\hline & $283-308$ & 0,225 & $0,0210,118$ & 0,077 & 0,056 & 0,018 & 0,309 & 0,525 & 2,254 & 0,238 & 0,051 \\
\hline
\end{tabular}

TABELA 3 - Taxa de acumulação líquida organogênica (TALON) e taxa de absorção relativa (TARN) de nutrientes nos diferentes órgãos de mudas de caramboleira 'Golden Star', cultivadas em solução nutritiva.

\begin{tabular}{|c|c|c|c|c|c|c|c|c|c|c|c|c|}
\hline \multirow[t]{3}{*}{ rgãos } & ríodos & $\mathrm{N}$ & $\mathrm{P}$ & K & $\mathrm{Ca}$ & $\mathrm{Mg}$ & S & B & $\mathrm{Cu}$ & $\mathrm{Fe}$ & $\mathrm{Mn}$ & $\mathrm{Zn}$ \\
\hline & di & & & 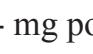 & . & dis & & \multicolumn{5}{|c|}{--------- $\mu \mathrm{g}$ por g por dia ------- } \\
\hline & & & & & & & & & & & & \\
\hline \multirow{4}{*}{ aízes } & 24 & 0,122 & 0 , & 0,067 & 0 , & & 0,028 & 172 & 0,385 & 1,369 & 010 & 0,004 \\
\hline & 233 & 692 & 0 & 0 , & 0 & 8 & 21 & 97 & 0,295 & & 0,527 & 0,496 \\
\hline & 258 & 0,225 & 0,064 & 0,063 & 0,027 & 0,014 & 0,017 & 0,243 & 0,671 & 12,139 & 0,275 & 0,011 \\
\hline & 283 & 14 & & & & & & & 29 & & & 0,209 \\
\hline \multirow{4}{*}{ au } & 208 & 0,134 & 0,0 & 0,257 & 0,1 & 0 & 0 , & & 0,211 & & 0,011 & 0,012 \\
\hline & 23 &, 523 & 0 & & 0 , & 0 & 0 , & 35 & 0,515 & & 38 & 0,604 \\
\hline & 258 & 0,037 & 2 & 0 , & 0,016 & 4 & 0,002 & 0,265 & 0,876 & 0,774 & 0,213 & 0,445 \\
\hline & 283 & & & & 0,0 & & & & 0,811 & & & 0,046 \\
\hline \multirow{5}{*}{ blha } & & 5 & & 0 & 0 & 8 & & 04 & 77 & & 38 & 0,830 \\
\hline & $233-$ & 0,585 & 0 & 0,172 & 0,057 & 0,030 & 0,002 & 0,806 & 0,308 & 0,628 & 2,484 & 0,013 \\
\hline & & & & & 0,2 & 0,115 & 0 , & 57 & 0,410 & 5,429 & 2,535 & 0,312 \\
\hline & 283 & 0,225 & 0,009 & 0,158 & 0,040 & 0,038 & 0,020 & 0,400 & 0,046 & 0,293 & 0,426 & 0,028 \\
\hline & \multicolumn{12}{|c|}{ TARN } \\
\hline \multirow{4}{*}{ nteira } & & 3 & & & 0 & 0,101 & 0,066 & 1 & 0 & & 6 & 0,322 \\
\hline & 23 & & & 0,274 & 0,1 & & & 0,457 & 0,372 & 3 , & 1,249 & 0,336 \\
\hline & & & & & 0,0 & & & & 0,625 & & 1,204 & 0,279 \\
\hline & 283-308 & 187 & 0,016 & 0,146 & 0,041 & 0,041 & 0,012 & 0,255 & 0,328 & 0,190 & 0,291 & 0,071 \\
\hline
\end{tabular}


A

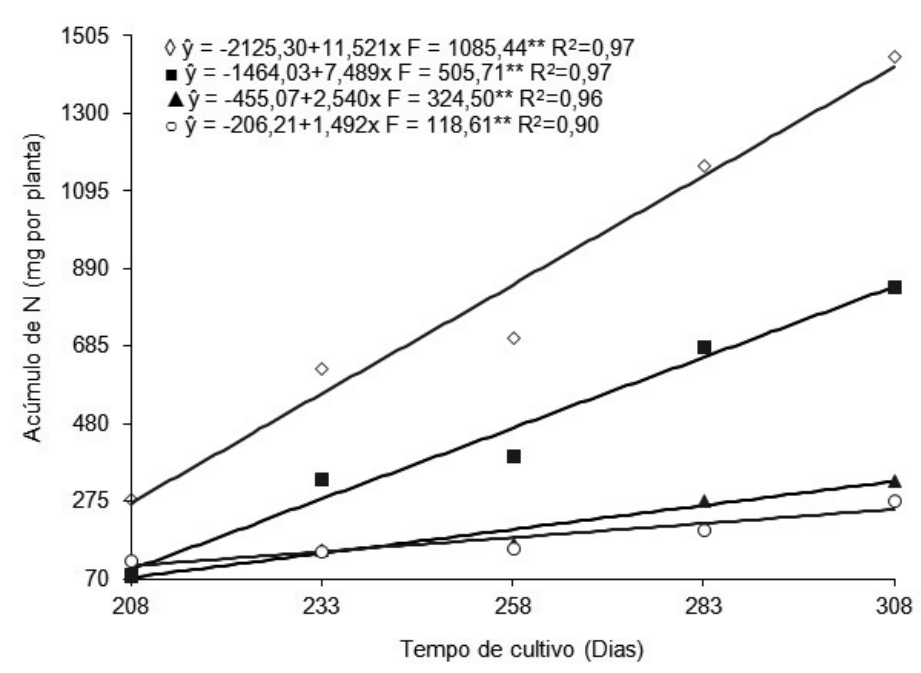

B

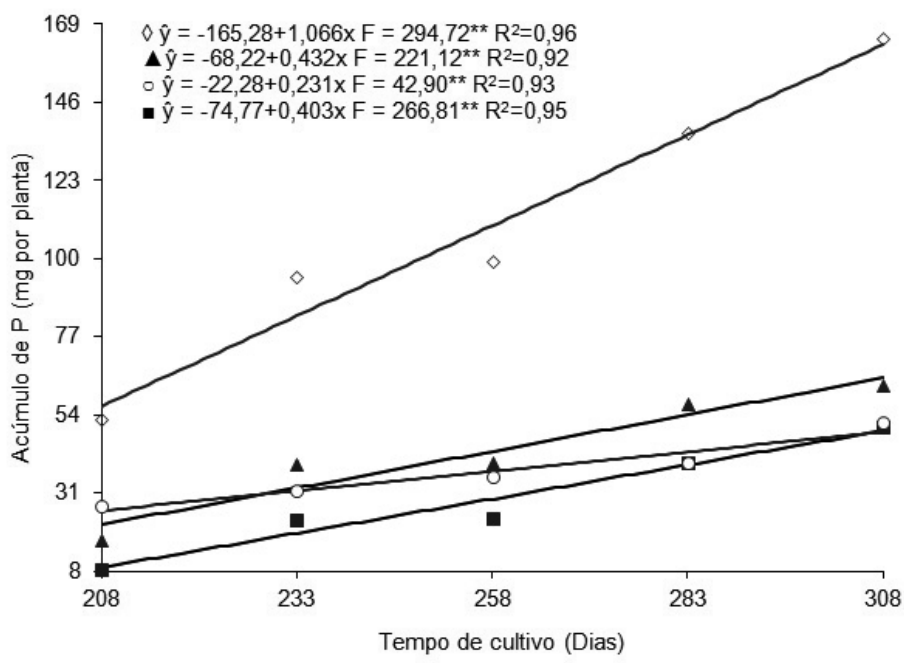

C

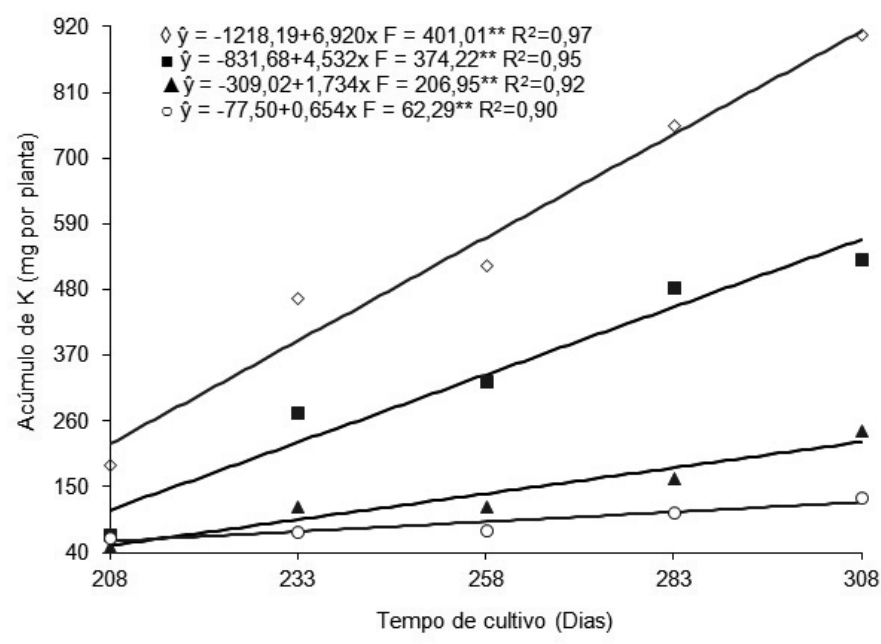

continua... 
continuação...

$\mathrm{D}$

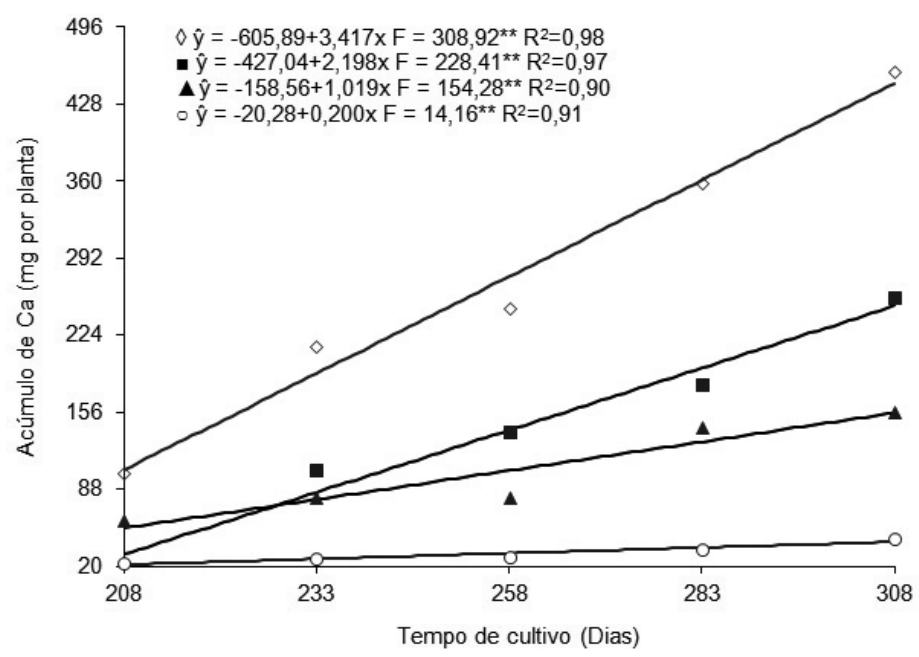

$\mathrm{E}$

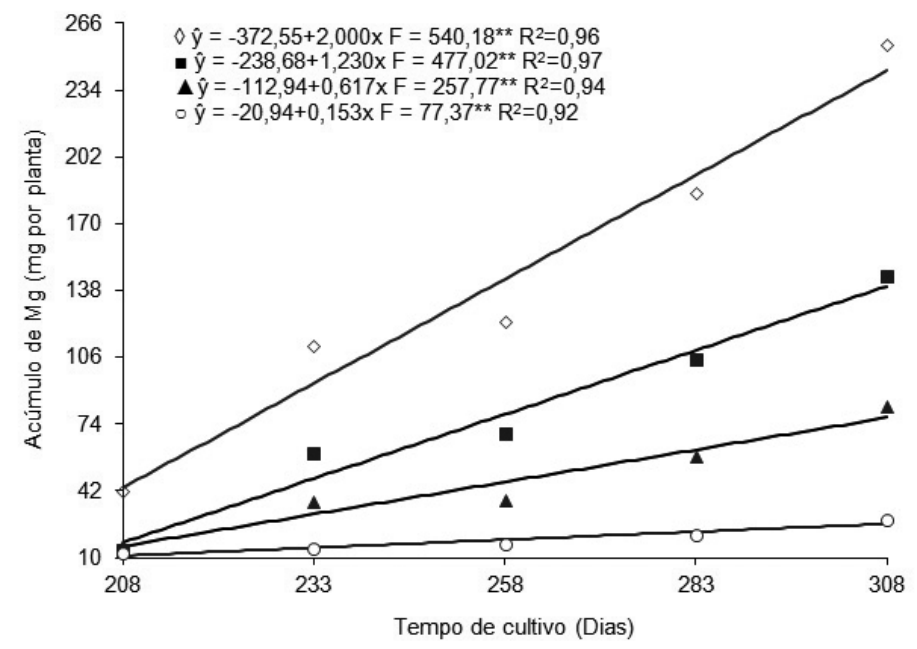

F

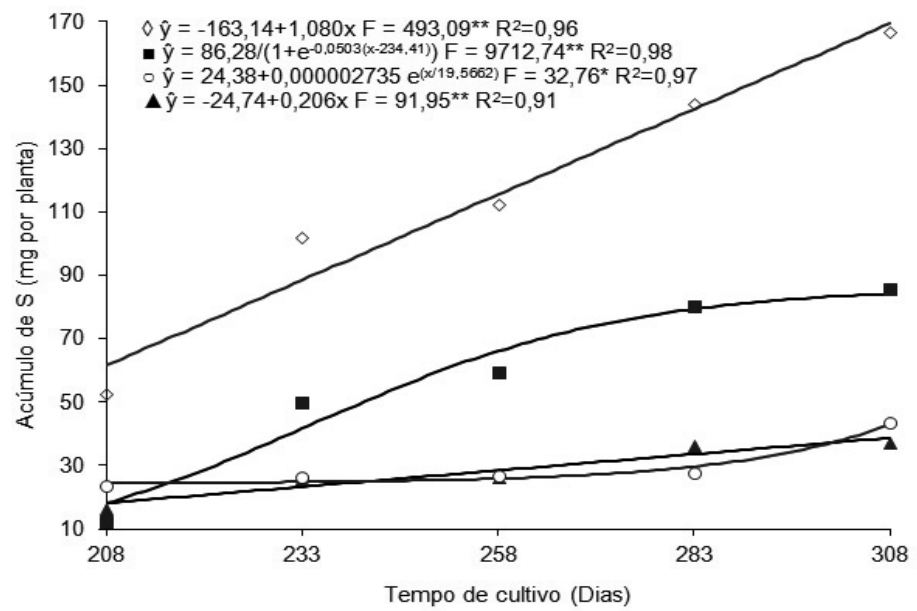

FIGURA 1- Valor de F e coeficiente de determinação $\left(\mathrm{R}^{2}\right)$ obtidos nos estudos de regressão sobre os efeitos do tempo de cultivo (dias) no acúmulo de $\mathrm{N}$ (a), P (b), K (c), Ca (d), Mg (e) e S (f) na planta inteira $(\diamond)$, nas folhas $(\boldsymbol{\square})$, no caule $(\boldsymbol{\Delta})$ e nas raízes $(\circ)$ em mudas de caramboleiras 'B-10', cultivadas em solução nutritiva. (**,*: $\mathrm{p}<0,01$ e $\mathrm{p}<0,05$, respectivamente). 
A

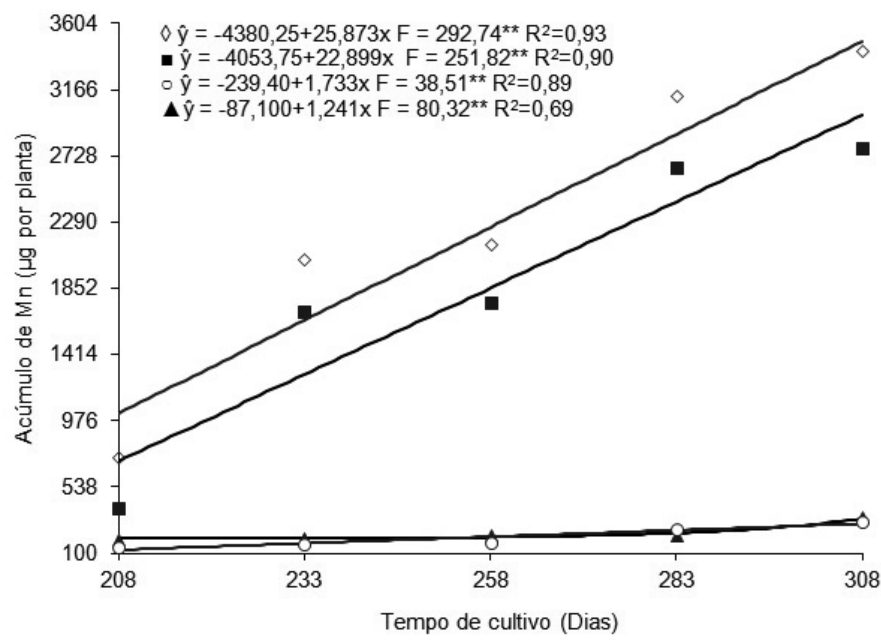

B

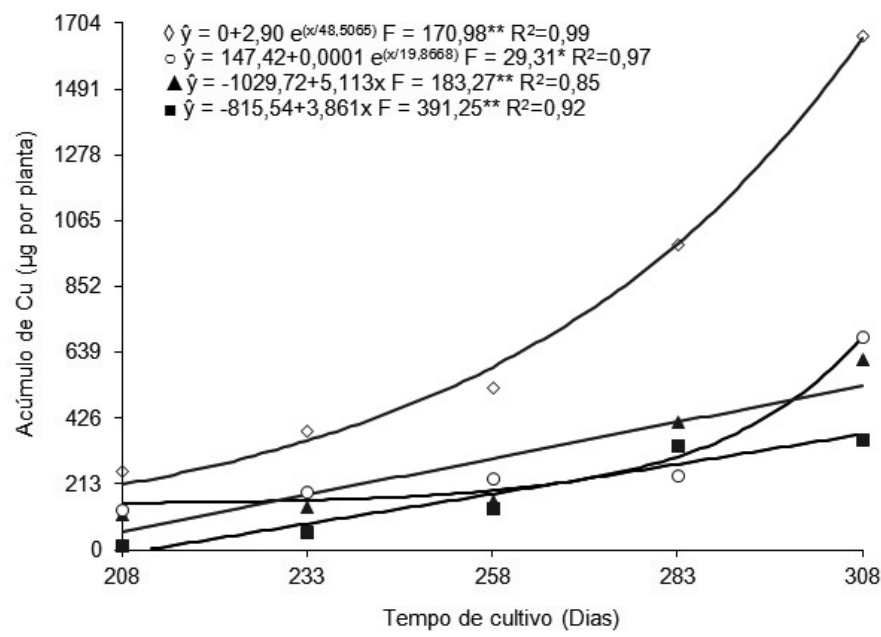

$\mathrm{C}$

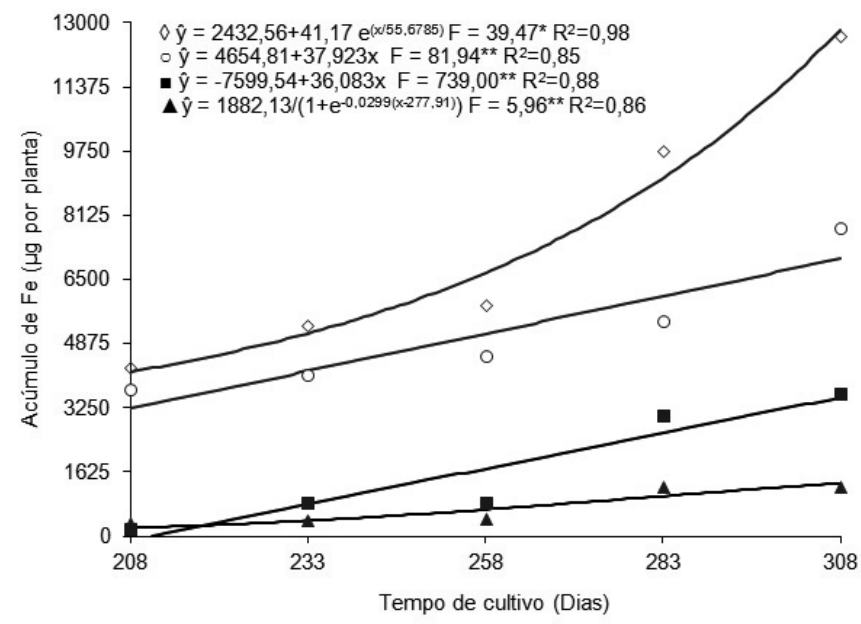


continuação...

D

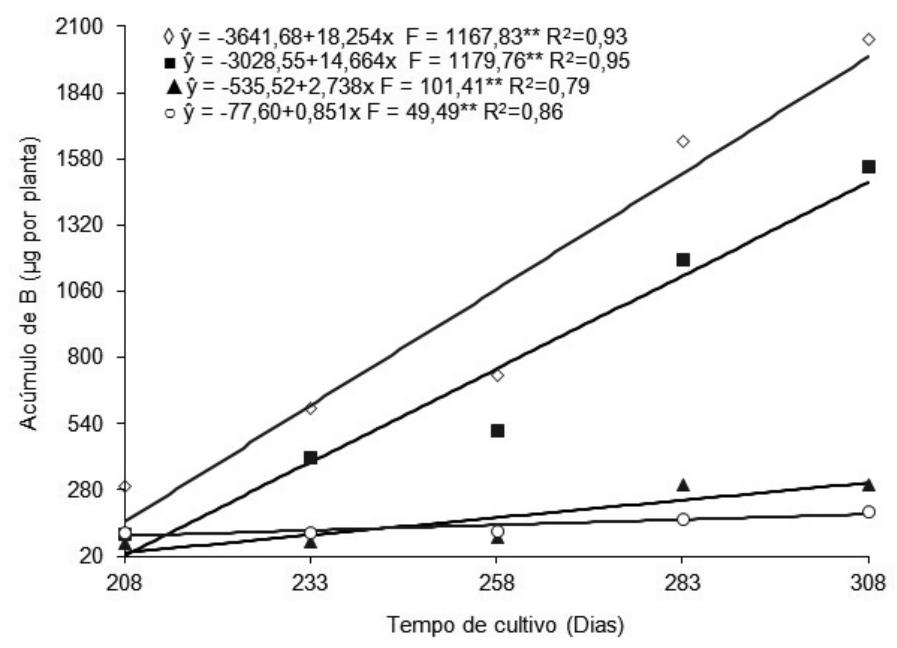

$\mathrm{E}$

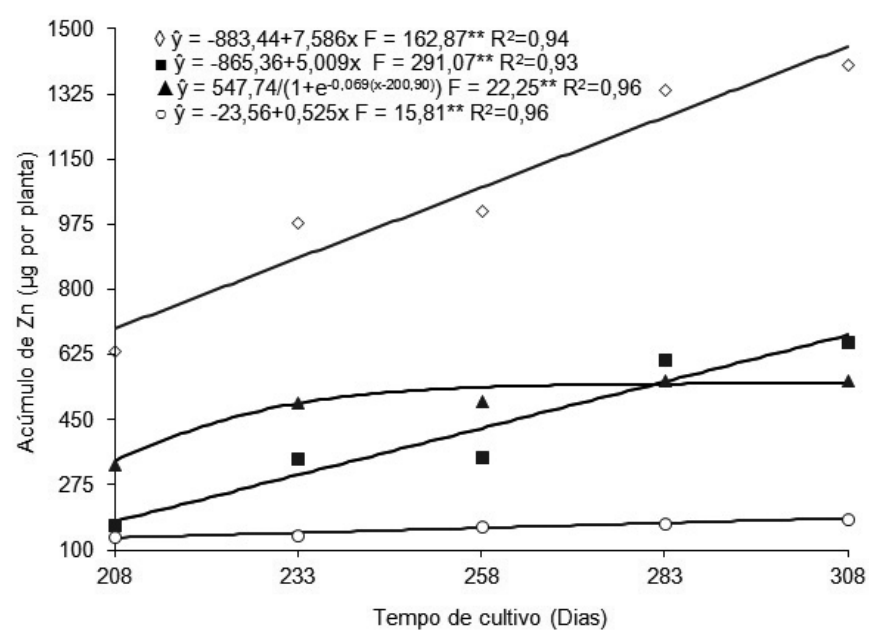

FIGURA 2 - Valor de F e coeficiente de determinação $\left(\mathrm{R}^{2}\right)$ obtidos nos estudos de regressão sobre os efeitos do tempo de cultivo (dias) no acúmulo de B (a), Cu (b), Fe (c), Mn (d) e Zn (e) na planta inteira $(\diamond)$, nas folhas $(\boldsymbol{\nabla})$, no caule $(\boldsymbol{\Delta})$ e nas raízes $(\circ)$, em mudas de caramboleiras 'B-10', cultivadas em solução nutritiva. ( $* * * *: p<0,01$ e $\mathrm{p}<0,05$, respectivamente). 
A

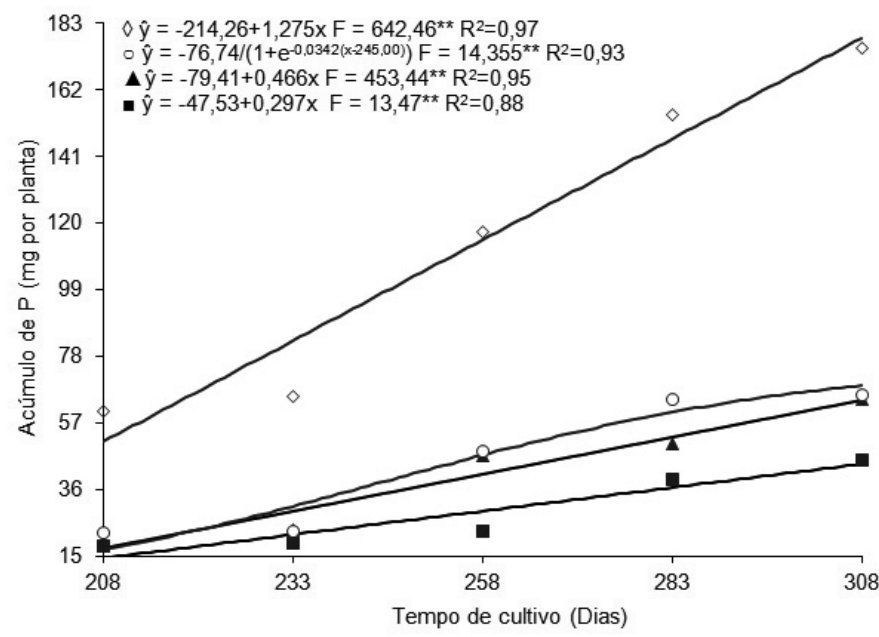

B

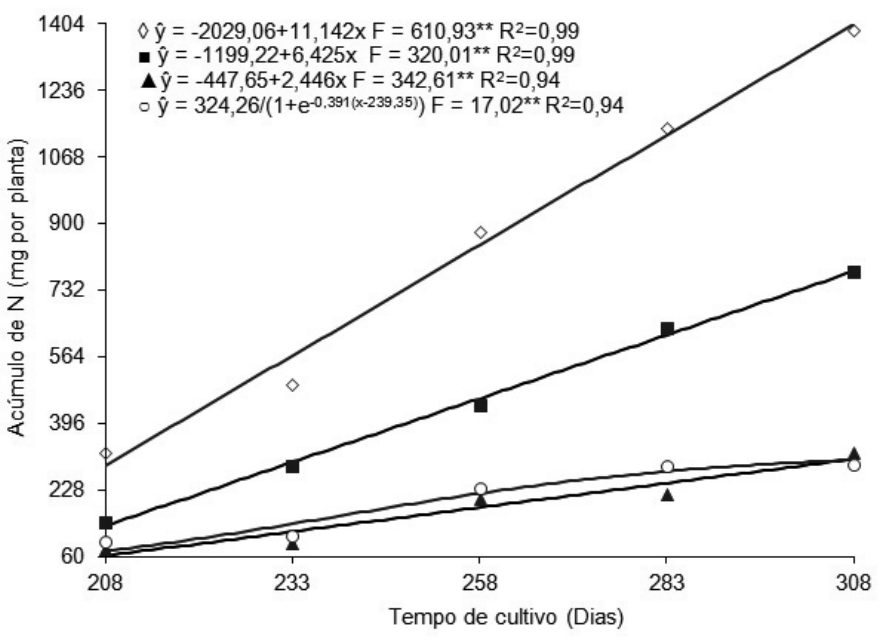

C

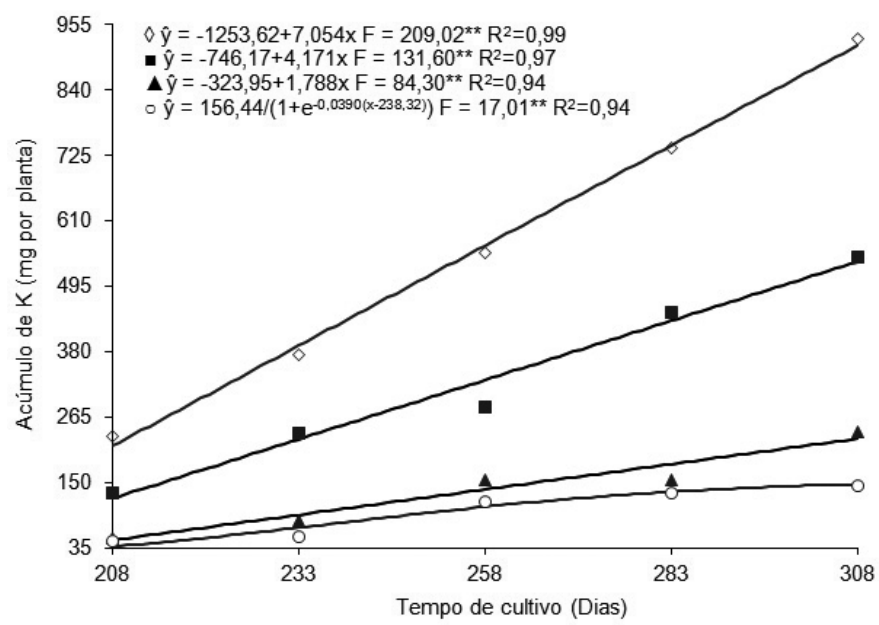

continua... 
continuação...

$\mathrm{D}$

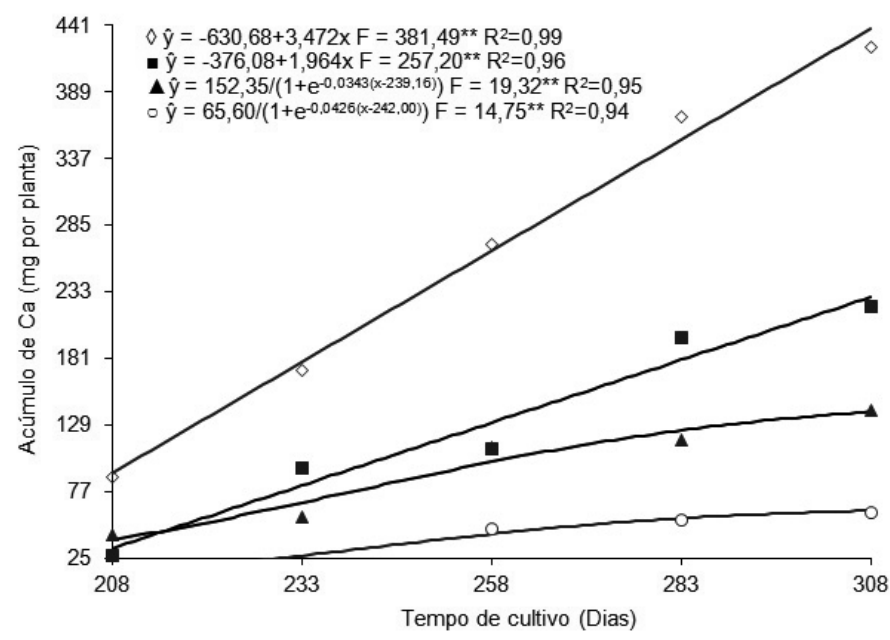

$\mathrm{E}$

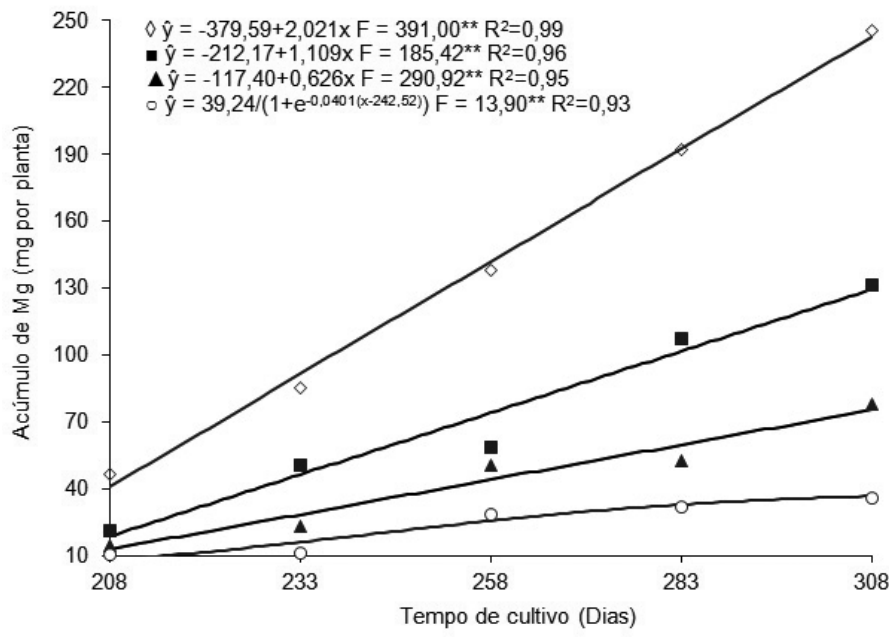

$\mathrm{F}$

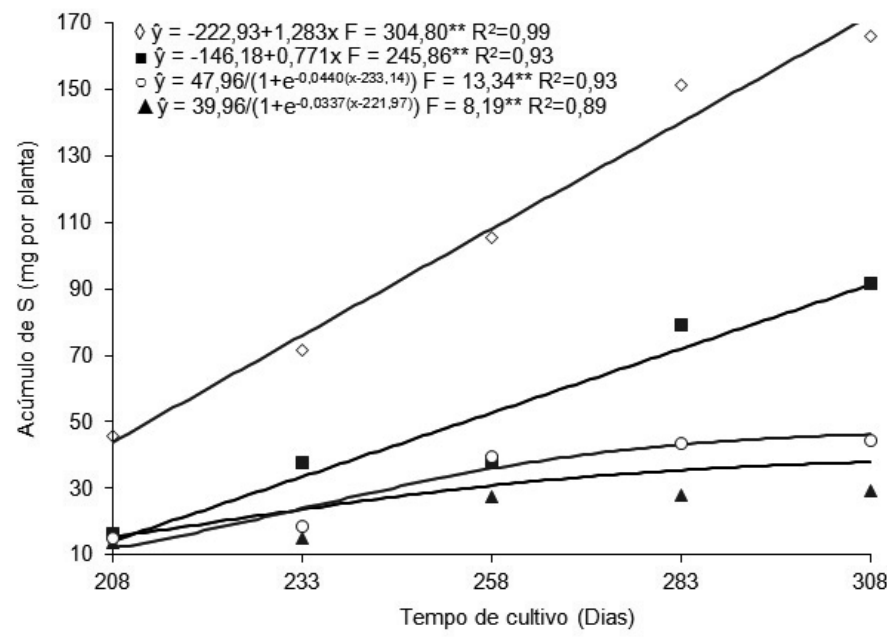

FIGURA 3 - Valor de F e coeficiente de determinação $\left(\mathrm{R}^{2}\right)$ obtidos nos estudos de regressão sobre os efeitos do tempo de cultivo (dias) no acúmulo de $\mathrm{N}$ (a), P (b), K (c), Ca (d), Mg (e) e S (f) na planta inteira $(\diamond)$, nas folhas $(\boldsymbol{\bullet})$, no caule $(\boldsymbol{\Delta})$ e nas raízes $(\circ)$, em mudas de caramboleiras 'Golden Star', cultivadas em solução nutritiva. $(* *: p<0,01)$. 
A

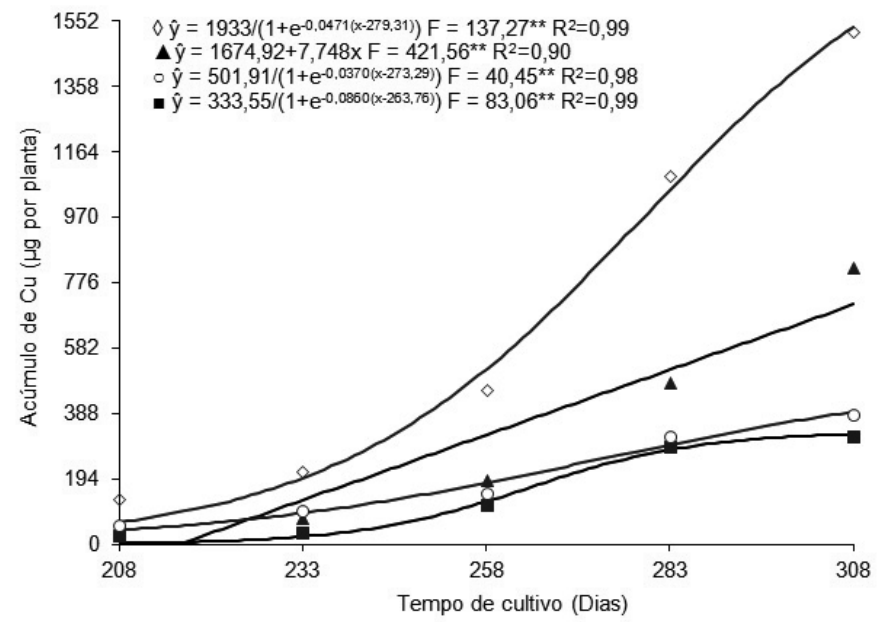

B

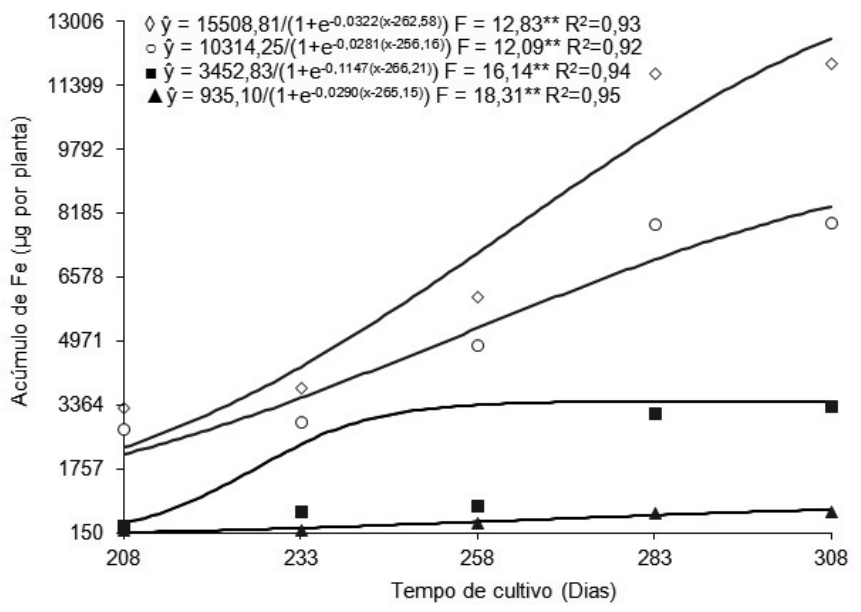

$\mathrm{C}$

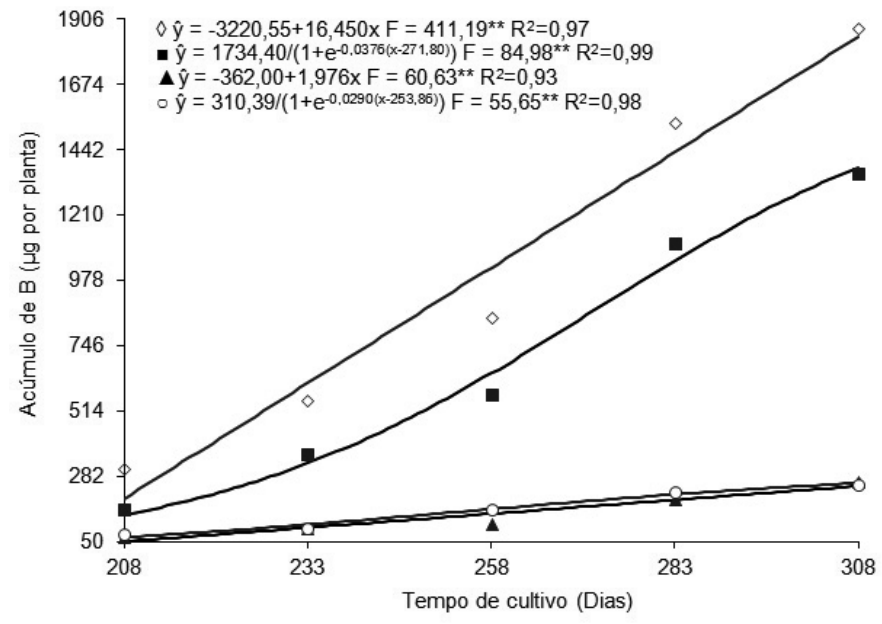

continua... 
continuação

$\mathrm{D}$

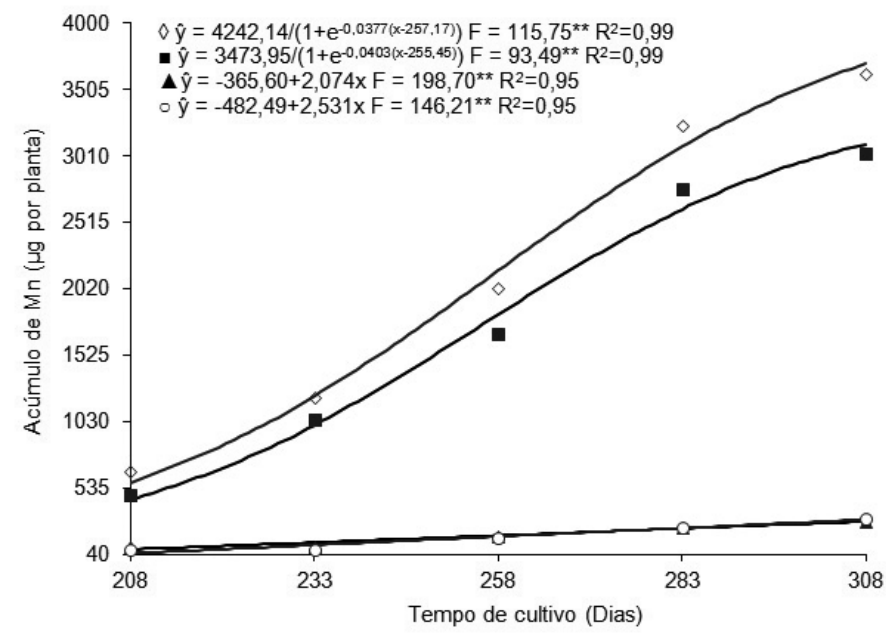

E

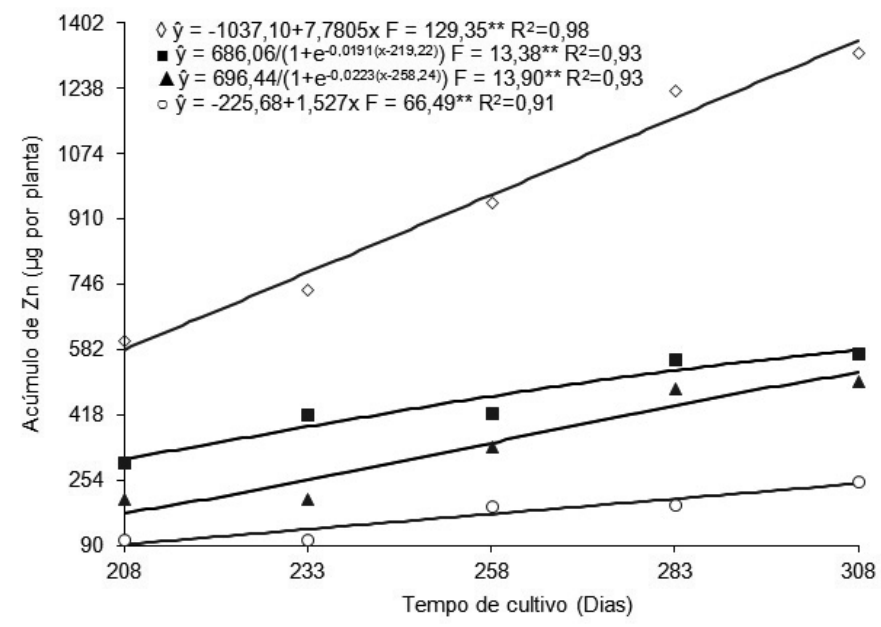

FIGURA 4 - Valor de F e coeficiente de determinação $\left(\mathrm{R}^{2}\right)$ obtidos nos estudos de regressão sobre os efeitos do tempo de cultivo (dias) no acúmulo de B (a), Cu (b), Fe (c), Mn (d) e Zn (e) na planta inteira $(\diamond)$, nas folhas $(\boldsymbol{\nabla})$, no caule $(\boldsymbol{\Delta})$ e nas raízes $(\circ)$, em mudas de caramboleiras 'Golden Star', cultivadas em solução nutritiva. $(* *: \mathrm{p}<0,01)$. 


\section{CONCLUSÕES}

1-Não há diferenças no acúmulo de nutrientes nas mudas de caramboleiras de ambas as cultivares, sendo que a ordem decrescente dos mesmos, em cada muda de 'B-10', no final do período experimental, foi: $\mathrm{N}>\mathrm{K}>\mathrm{Ca}>\mathrm{Mg}>\mathrm{S}>\mathrm{P}>\mathrm{Fe}>\mathrm{Mn}>\mathrm{B}>\mathrm{Cu}>$ Zn. Para a 'Golden Star', a ordem foi: $\mathrm{N}>\mathrm{K}>\mathrm{Ca}>$ $\mathrm{Mg}>\mathrm{P}>\mathrm{S}>\mathrm{Fe}>\mathrm{Mn}>\mathrm{B}>\mathrm{Cu}>\mathrm{Zn}$.

2-Para as duas cultivares, o acúmulo médio é maior nas folhas $>$ caule $>$ raízes. O período de maior exigência para 'B-10'é entre 208 - 233 e, para 'Golden Star', entre 233 - 283 dias após o transplantio.

3-As diferentes taxas de acumulação líquida dos nutrientes, nos diferentes órgãos da caramboleira, nem sempre acompanham a taxa de acumulação de nutrientes do respectivo órgão.

\section{REFERÊNCIAS}

AUGOSTINHO, L. M. D.; PRADO, R. de M.; ROZANE, D. E.; FREITAS, N. Marcha de absorção de macro e micronutrientes em mudas de goiabeira 'Pedro Sato'. Bragantia, Campinas, v.67, n. 3, p.563-568, 2008

BARBOSA, Z.; SOARES, I.; CRISÓTOMO, L. A. Crescimento de nutrientes por mudas de gravioleira. Revista Brasileira de Fruticultura, Jaboticabal, v.25, n.3, p.519-522, 2003.

BATAGLIA, O. C.; FURLANI, A. M. C.; TEIXEIRA, J. P. F.; FURLANI, P. R.; GALLO, J. R. Métodos de análise química de plantas. Campinas: Instituto Agronômico, 1983. 48p. (Boletim Técnico, 78).

CHU, E. Y.; MÖLLER, M. R. F.; CARVALHO, J. G. Efeitos da inoculação micorrízica em mudas de gravioleira em solo fumigado e não fumigado. Pesquisa Agropecuária Brasileira, Brasília, v.36, n.4, p.671-680, 2001.

ESTAT: sistema para análises estatísticas (v.2.0). Jaboticabal: Polo Computacional, Departamento de Ciências Exatas FCAV/UNESP, 1992.

FRANCO, C. F.; PRADO, R. de M.; BRAGHIROLLI, L. F.; ROZANE, D. E. Marcha de absorção dos micronutrientes para mudas de goiabeiras cultivares Paluma e Século XXI. Bragantia. Campinas, v.67, n.1, p.83-90, 2008.
FRANCO, C. F.; PRADO, R. de M.; BRAGHIROLLI, L. F.; ROZANE, D. E. Curva de crescimento e marcha de absorção de macronutrientes em mudas de goiabeira. Revista Brasileira de Ciência do Solo, Viçosa, MG,v.31, n.6, p.1429-1437, 2007.

FREITAS, N. Curva de crescimento e marcha de absorção de nutrientes emudas de caramboleira 'Nota-10'. 2008. 81f. Monografia (Trabalho de Graduação em Agronomia) - Faculdade de Ciências Agrárias e Veterinárias,Universidade Estadual , Jaboticabal, 2008.

HOFFMAM, R.; VIEIRA, S. Análise de regressão. São Paulo: Huitec-Edusp, 1977. 339p.

LIMA FILHO, O. F.; MALAVOLTA, E.; SENA, J. O. A.; CARNEIRO, J. W. P. Absorção e acumulação de nutrientes em estévia (Stevia rebaudiana (Bert.) Bertoni): II. Micronutrientes. Scientia Agricola, Piracicaba, v.54, n.1-2, p.23-30, 1997 b.

LIMA FILHO, O. F.; MALAVOLTA, E.; SENA, J. O. A.; CARNEIRO, J. W. P. Absorção e acumulação de nutrientes em estévia (Stevia rebaudiana (Bert.) Bertoni): I. Macronutrientes. Scientia Agricola, Piracicaba, v.54, n.1-2, p.14-22, 1997a.

MARSCHNER, H. Mineral nutrition of higher plants. $2^{\text {nd }}$ ed. San Diego: Academic Press, 1995. 889 p.

ROZANE, D. E.; PRADO, R. de M.; FRANCO, C. F.;NATALE, W. Eficiência de absorção, transporte e utilização de macronutrientes por porta-enxertos de caramboleira, cultivados em soluções nutritivas. Ciência e Agrotecnologia, Lavras, v.31, n.4, p.10201026, 2007.

ROZANE, D. E.; PRADO, R. de M.; NATALE, W.; ROMUALDO, L. M.; SOUZA, H. A. de I. Produção de mudas de caramboleiras 'B-10' E 'Golden Star': I - Parâmetros biológicos. Revista Brasileira de Fruticultura, Jaboticabal, v.33, n.4, p.1303-1310, 2011.

WELBANK, P. J. The effects of competition with Agropyron repens and of nitrogen and water supply on the nitrogen content of Impatiens parviflora. Annals of Botany, Oxford, v.26, n.103, p.361-373, 1962. 